Available online at GSC Online Press Directory

GSC Biological and Pharmaceutical Sciences

e-ISSN: 2581-3250, CODEN (USA): GBPSC2

\title{
Antioxidant, antibacterial activities and phytochemical screening of Asteriscus pygmaeus aerial parts ethanolic extract
}

\author{
Shafik Nabila Helmy*, Shafek Reham Ezzat and Michael Helana Naguib \\ Chemistry of Tanning Materials and Leather Technology Department, National Research Centre, Dokki, Cairo, Egypt.
}

Publication history: Received on 20 November 2019; revised on 12 December 2019; accepted on 13 December 2019

Article DOI: https://doi.org/10.30574/gscbps.2019.9.3.0218

\begin{abstract}
Phytochemical investigation of the Aerial parts of Asteriscus pygmaeus ethanolic extract gave rise to isolation of a new compound: 6-Hydroxykaempferol 6-methylether (eupafolin) -4' glucopyranoside (1) together with eight known metabolites; patuletin 7-glucoside (2), chrysoeriol 7- $O$ - glucoside (3), 6-Hydroxy kaempferol (4), 6-Hydroxy kaempferol 6-methyl ether (eupafolin) (5), 6,4 dimethoxy luteolin (6), patuletin (7), chrysoeriol (8) and luteolin (9). Their structures were established by chromatographic methods, chemical degradation and various spectroscopic data; compared with previously known analogues. Antioxidant activity of ethanolic extract was investigated using DPPH (2,2-diphenyl-1picrylhydrazyl) as stable radicals method indicated a high radical scavenging activity for it. The results for antimicrobial study for extract against bacteria and fungi showed that it exhibited broad spectrum of antimicrobial activity against gram positive bacteria, gram negative bacterial and fungal cultures.
\end{abstract}

Keywords: Asteraceae; Asteriscus pygmaeus; flavonoids, Antioxidant; Antibacterial activities

\section{Introduction}

Up to date, there has been great attention for search about antimicrobial and antioxidants compounds from natural sources to manage plant and human diseases [1]. Natural antioxidants slow down the oxidative damage of food products and may help in prevention the neurodegenerative, inflammation [2] and ageing disease [3]. All the time, the market addresses its interest to secondary metabolites which produced by plants to confirm their properties and use them in industry. Also, now a day the scientist search about antimicrobial agents due to increasing the resistance of microorganisms which used in antimicrobial drugs. Many natural products e.g flavonoids, phenolics, terpenes and coumarins are characterized as metabolites which permit easy transport across the cell membranes to stimulate different biological activities such as anticholinesterase, antiinflammatory and antioxidant effects [4]. Asteriscus pygmaeus plant under investigation, belongs to Asteraceae family which consists of eight species and five sub-species extend from North Africa to the desert regions of Asia [5]. According to literature, Asteriscus genera are characterized by a high content of flavonoids, phenolics [6], [7], sesquiterpenes [5], bisabolone [8] and hydroperoxides [9]. Antimicrobial and antioxidant activities of some Asteraceae extracts constituents have documented [10-12] against many fungal and bacterial pathogens $[13,14]$. The genus plants are famous with compounds that has potential antispasmodic, antitumor, and anti-inflammatory activities, and they used in treatment of infected wounds [15]. Some plants of this genus e.g. Asteriscus graveolens are used in folk medicine for treating fever, stomachic, cephalic pains, gastrointestinal tract complaints, insect repellent, headache bronchitis and bleeding [16]. The objective of this study is to isolation and identification of the polyphenolic content of the Aerial parts of Asteriscus pygmaeus ethanolic extract and evaluate its antioxidant, antimicrobial activities. Results showed that the ethanolic extract contain eight flavonoid compounds among them one new natural compound; eupafolin -4'-glucopyranoside [1] which was isolated for the first time in nature.

\footnotetext{
${ }^{*}$ Corresponding author

E-mail address: nabilashafik@yahoo.com
} 


\section{Material and methods}

\subsection{General methods}

${ }^{1} \mathrm{H}$ and ${ }^{13} \mathrm{C}(500,125 \mathrm{MHz}) \mathrm{NMR}$ : Joel spectrometer in DMSO-d6; UV: Shimadzu spectrophotometer model UV-240 (Kyoto, Japan); column chromatography (CC): Polyamide 6S (Riedel, De Häen), Cellulose (Merck) and Sephadex LH-20 (Pharmacia); paper chromatography (PC): Whatman No. 1 and preparative (PPC) on 3 MM paper using the following solvent systems: (1) BAW (n-BuOH/AcOH/H2O, 6:1:2); (2) $\mathrm{AcOH} / \mathrm{H}_{2} \mathrm{O}$ (15:85), (3) $\mathrm{PhOH}$.

\subsection{Plant material}

The Asteriscus pygmaeus was collected from west of Mersa - Matruh (Wadi-Um El-Rakhm). A voucher specimen is deposited in the National Research Centre Herbarium.

\subsection{Extraction and fractionation}

$750 \mathrm{~g}$ of powdered air-dried Asteriscus pygmaeus was extracted with $80 \%$ EtOH. Its ethanolic extract was vacuum dried at $55^{\circ} \mathrm{C}$ yielding $350 \mathrm{~g}$. Its TDPC using the solvent systems (1) and (2), respectively, revealed the presence of many components of polyphenolic nature. The concentrated extract was chromatographed on a polyamide column; elution being performed with water followed by water ethanol mixtures to give six fractions. These fractions were further chromatographed on paper and subcolumn chromatography to isolate and purified their flavonoid constituents using various solvents to afford nine natural flavonoid compounds among of them one new compound: -6-Hydroxy kaempferol- 6-methyl ether (eupafolin) -4' glucopyranoside (1) together with eight known metabolites;patuletin 7glucoside (2), chrysoeriol 7- 0-glucoside(3), 6-Hydroxykaempferol (4),6-Hydroxykaempferol 6-methyl ether (eupafolin) (5), 6,4 dimethoxyluteolin (6), patuletin(7),chrysoeriol(8) and luteolin(9). Their chemical structures have been established by conventional methods of chemical and physical analysis and confirmed by NMR spectroscopy.

\subsection{Evaluation of Antioxidant activity}

The potential antioxidant activity of the ethanolic extract of aerial parts of Asteriscus pygmaeus extract (AE) was assessed on the basis of the scavenging activity of the stable (DPPH) free radical (Gamezet al., 1998) [17]. Weighed samples were dissolved in distilled DMSO and $10 \mu \mathrm{L}$ of each or an ascorbic acid aqueous standard (from $0-100 \mu \mathrm{g} / \mathrm{mL}$ ), was added to $90 \mu \mathrm{L}$ of $100 \mu \mathrm{M}$ DPPH (Sigma, St. Louis, MO) in ethanol solution in a 96-well micro-titer plate. After incubation in the dark at $37^{\circ} \mathrm{C}$ for $30 \mathrm{~min}$, the decrease in absorbance of each solution was measured at $515 \mathrm{~nm}$ using an ELISA micro-plate reader (Blo Rad, model 550). Absorbance of a blank containing an equal volume of DMSO and DPPH solution was prepared and measured as well. Percentage DPPH radical scavenging activity $=1-\left[\mathrm{A}_{\text {sample }} / \mathrm{A}_{\text {control }}\right]$ x 100, where $A_{\text {sample and }} A_{\text {control }}$ are absorbance of sample and control, respectively. The concentration of sample required to scavenge $50 \%$ of DPPH (IC50) was determined. Decreasing of the DPPH solution absorbance indicates an increase of the DPPH radical scavenging activity. The experiment was carried out in triplicate.

\subsection{Antimicrobial activity of the plant extract}

\subsubsection{Test microorganisms}

The following clinical isolates of bacteria and fungi were used for the study: Pseudomonas aeruginosa, Klebsiella pneumoniae, Escherichia coli, Staphylococcus aureus, Micrococcus luteus, Salmonella typhi, Candida albicans, and C. tropicalis. Microbial cultures were grown on nutrient agar and potato extrose agar for bacteria and fungi, respectively, and maintained at $4^{\circ} \mathrm{C}$ in a refrigerator for further studies.

\subsubsection{Controls used in the study}

Bacitracin $(10 \mu \mathrm{g} / \mathrm{disc})$ was used as positive control for S. aureus; Erythromycin $(10 \mu \mathrm{g} / \mathrm{disc})$ was used for $P$. aeruginosa,

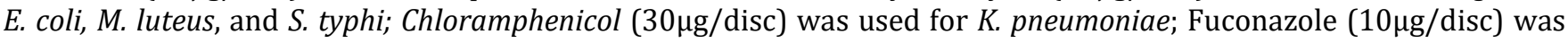
used for C. albicans and C. tropicalis. Sterilized distilled water was used as negative control for the study.

\subsubsection{Antimicrobial assay}

Antimicrobial activity of the tested extract was determined by the agar well diffusion method [18]. All test organisms were inoculated on MHB (Mueller Hinton broth) and PDB (Potato Dextrose broth) for 8 hours. Microbial isolates were inoculated on MHA (Mueller Hinton agar) plates and PDA (Potato Dextrose agar) plates by using sterile cotton swabs for bacteria and fungi, respectively. Agar surface was bored by using sterilized gel borer to make wells (7 mm diameter). 
$100 \mu \mathrm{l}$ of the tested extracts and $100 \mu \mathrm{l}$ of sterilized distilled water (negative control) were poured in to separate wells. The standard antibiotic disc was placed on the agar surface as positive control. Bacterial plates were incubated at $37^{\circ} \mathrm{C}$ for 24 hours and fungal plates were incubated at room temperature for 48 to 72 hours. Experiment was performed in triplicates.

\subsubsection{Determination of relative percentage inhibition}

The relative percentage inhibition of the test extracts and the isolated compounds with respect to positive control was calculated by using the following formula $[19,20]$.

Relative percentage inhibition of the test extract $=100 \times(X-Y) /(Z-Y)$

Where,

$\mathrm{x}$ : total area of inhibition of the test extract

$y$ : total area of inhibition of the solvent

z: total area of inhibition of the standard drug

The total area of the inhibition was calculated by using area $=\pi r 2$; where, $r=$ radius of zone of inhibition.

\subsection{Statistical Analysis}

The values of antimicrobial activity of the test extract of Asteriscus pygmaeus are expressed as mean \pm standard deviation of the response of 3 replicates determinations per sample.

\subsection{Spectral data}

\subsubsection{New natural eupafolin -4' glucopyranoside [1]}

Rf-values x100: 61 (1), 24 (2), 29 (3); UV $\lambda \max$ nm (MeOH): 241sh, 252, 268, 290, 325sh, 355; +NaOMe: 272, 302sh, 393; + NaOAc: 270sh, 267, 328, 397; +NaOAc/H3BO3: 252sh, 270, 350; + AlCl3: 266sh, 272, 295, 360, 392; +AlCl3 / HCl: 262 sh, 275, 295, 350, 382;

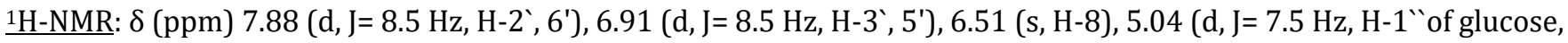
4.07-3.95 (m, glucose protons), $3.8\left(\mathrm{~s}, \mathrm{CH}_{3}\right.$ of the methyl gp).

13C-NMR spectral data: Aglycone moiety: (ppm) 147.7 (C-2), 135.6 (C-3), 176.2 (C-4), 151.7 (C-5), $131.2(\mathrm{C}-6), 157.1$ (C7), 93.8 (C-8), 151.4 (C-9), 103.7 (C-10), 124.1 (C-1'), 129.1(C-2`), 116.6 (C-3`), 157.2 (C-4'), 116.6 (C-5'), $129.2^{\prime}\left(\mathrm{C}^{\prime} 6^{\prime}\right)$ ), 99.8 (C1“), 73.5 (C2“), 76.5(C3“), 69.8 (C4“), 77.3 (C5“), 60.5 (C6“), 56.0(5-OCH3).

\section{Results and discussion}

The aerial parts of Asteriscus pygmaeus were air- dried ground and extracted with $80 \%$ ethanol then applied to polyamide column. Elution of its 6 fractions was done using water followed by 10\% EtOH, 20\% EtOH,.... , 100\% EtOH. Nine compounds were isolated and purified using sub-columns or preparative PC for each fractions which were identified as following: eupafolin -4' glucopyranoside [6-Hydroxykaempferol 6-methyl ether (eupafolin)] (1) together with eight known metabolites; , patuletin 7-glucoside (2), 6,4 dimethoxyluteolin(3),chrysoeriol 7- 0 - glucoside(4), 6Hydroxykaempferol 6-methyl ether (eupafolin) (5), 6-Hydroxykaempferol (6), patuletin(7), chrysoeriol(8) and luteolin (9). The flavonol nature of compound (1) was confirmed from its color properties, Rf-values in addition to its UV spectral data in $\mathrm{MeOH}$ and with diagnostic reagents [21].

The aglycone 6-OH kaempferol-6-mehylether and the sugar glucose were obtained by complete acid hydrolysis which that was ensured by enzymatic hydrolysis using $\beta$-glucosidase. 6-OH kaempferol was obtained by demethylation of compound [1] using pyridmium chloride [21]. ${ }^{1} \mathrm{H}-\mathrm{NMR}$ spectral data of compound (1) achieved its structure as eupafolin -4 ' glucopyranoside whereby the doublet signals of H-3 ( $\delta 6.7 \mathrm{ppm}), \mathrm{H}-6$ ( $\delta 6.2 \mathrm{ppm})$ of the kaempferol were absent with the appearance of singlet signal of H-8 $(\delta 6.51 \mathrm{ppm})$. Appearance of a signal at $\delta 5.04 \mathrm{ppm}(\mathrm{d}, \mathrm{J}=7.5 \mathrm{~Hz}) \mathrm{with}$ a multiplet one at $\delta 3.1-3.6 \mathrm{ppm}$ ensure the presence of sugar glucose beside the presence of singlet signal at $\delta 3.8 \mathrm{ppm}$ were assignable for methoxy group[22]. Compound (1) structure was confirmed via its ${ }^{13} \mathrm{C}$-NMR spectrum data where the presence of a signal at $\delta 99.8 \mathrm{ppm}$ and the upfield shift of C-4 at $157.9 \mathrm{ppm}$ than the unsubstituted one (159.9) ppm, with the downfield shift of both $3^{`}$ and 5 'at 116.6 ppm than the unsubstituted one (115.4 ppm) ensured that position $4{ }^{\prime}$ was substituted with anomeric glucose. The presence of a methoxy group at position 6 was proved from the appearance 
of a signal at $\delta 56.0 \mathrm{ppm}$ and the downfield shift of C-6 at $131.2 \mathrm{ppm}$. From the previous data; compound (1) is deduced to be eupafolin -4' glucopyranoside and this compound was isolated for the first time from natural source.

Antioxidant activity of the aqueous ethanolic extract of Asteriscus pygmaeus showed a high activity as free- radical scavengers in the DPPH assay but still less than L-ascorbic acid (positive control).

Antimicrobial study of ethanolic extract against bacteria and fungi showed strong inhibitory activity against $S$. aureus, M. luteus, C. albicans, C. tropicalis, P. aeruginosa and E. coli while, S. typhiand K. pneumoniaewere found to be resistant towards .<smiles>[Y]c1ccc(C2=C([2H])C(=O)c3c(O)c([R])c(O)c([Y])c3C2)cc1[2H]</smiles>

Figure 1 Various compounds isolated from Asteriscus pygmaeus

$\mathrm{R}_{1}=\mathrm{OH}, \mathrm{R}_{3}=\mathrm{R}_{4}=\mathrm{R}_{5}=\mathrm{H} ; \mathrm{R}_{2}=\mathrm{OCH}_{3} ; \mathrm{R}_{6}=0$ - glucose; eupafolin -4 ' glucopyranoside (1)

$\mathrm{R}_{1}=\mathrm{R}_{4}=\mathrm{H} ; \mathrm{R}_{2}=\mathrm{OCH}_{3} ; \mathrm{R}_{3}=$ glucose; $\mathrm{R}_{5}=\mathrm{R}_{6}=\mathrm{OH} ;$ patuletin7-glucose (2)

$\mathrm{R}_{1}=\mathrm{R}_{2}=\mathrm{R}_{4}=\mathrm{H} ; \mathrm{R}_{3}=$ glucose; $\mathrm{R}_{5}=0-\mathrm{CH}_{3} ; \mathrm{R}_{6}=\mathrm{OH}$; chrysoeriol 7- $\mathrm{O}$ - glucoside (3)

$\mathrm{R}_{1}=\mathrm{R}_{2}=\mathrm{R}_{6}=\mathrm{OH}, \mathrm{R}_{3}=\mathrm{R}_{4}=\mathrm{R}_{5}=\mathrm{H} ; 6$ OH- kaempferol (4)

$\mathrm{R}_{1}=\mathrm{R}_{6}=\mathrm{OH}, \mathrm{R}_{3}=\mathrm{R}_{4}=\mathrm{R}_{5}=\mathrm{H} ; \mathrm{R}_{2}=0-\mathrm{CH}_{3} ; 6$ OH- kaempferol-6-methyl ether (5)

$\mathrm{R}_{1}=\mathrm{R}_{3}=\mathrm{R}_{4}=\mathrm{H} ; \mathrm{R}_{2}=\mathrm{R}_{6}=\mathrm{OCH}_{3} ; \mathrm{R}_{5}=\mathrm{OH} ; 6$,4 dimethoxy luteolin (6)

$\mathrm{R}_{2}=\mathrm{OCH}_{3}, \mathrm{R}_{1}=\mathrm{R}_{3}=\mathrm{R}_{4}=\mathrm{H} ; \mathrm{R}_{5}=\mathrm{R}_{6}=\mathrm{OH} ;$ patuletin (7)

$\mathrm{R}_{1}=\mathrm{R}_{2}=\mathrm{R}_{3}=\mathrm{R}_{4}=\mathrm{H} ; \mathrm{R}_{5}=\mathrm{OCH}_{3} ; \mathrm{R}_{6}=\mathrm{OH} ;$ chrysoeriol (8)

$\mathrm{R}_{1}=\mathrm{R}_{2}=\mathrm{R}_{3}=\mathrm{R}_{4}=\mathrm{H} ; \mathrm{R}_{5}=\mathrm{R}_{6}=\mathrm{OH} ;$ luteolin (9)

\subsection{DPPH radical scavenging activity}

The antioxidant activity of flavonoids means their ability to scavenge reactive oxygen species (ROS) e.g superoxide anions $\left(\mathrm{O}_{2-}^{-}\right)$, hydroxyl radicals $(\mathrm{OH})$ and lipid peroxy radicals perhaps the main function of flavonoids in the body as the oxidative stress is the most important cause for some disease in biological systems. so, the antioxidant activity of the aqueous ethanolic extract of Asteriscus pygmaeus was recorded in table 1 which indicate that it exhibited a high activity as free- radical scavengers in the DPPH assay but still less than L-ascorbic acid (positive control).

Table 1 antioxidant activity of the aqueous ethanolic extract of Asteriscus pygmaeus Values represent the mean \pm SD and mean of three replicates.

\begin{tabular}{|l|l|l|}
\hline Tested samples & AE & L-ascorbic acid \\
\hline DPPH (IC50) $\mu \mathrm{gmL}^{-1}$ & $36.06 \pm 0.71$ & $13.78 \pm 0.32$ \\
\hline
\end{tabular}

\subsection{Antimicrobial activity}

Ethanolic extract of Asteriscuspygmaeusexhibit broad spectrum of antimicrobial activity against Gram negative, Gram positive bacteria, and fungal cultures. Antimicrobial activity was measured as zone of inhibition and represented as 
mean \pm standard deviation $(\mathrm{n}=3)$. Extract exhibited maximum antimicrobial activity against $S$. aureus $(20.1 \pm 1.73)$, followed by M. luteus (12.59 \pm 1.74$)$. C. albicans(9.2 \pm 1.04$)$, C. tropicalis(6.63 \pm 1.30$)$, P. aeruginosa (5.5 \pm 2.05$)$ and E. coli $(3.37 \pm 1.51)$. Results are recorded in Table 2. S. typhiand $K$. pneumoniae were found to be resistant towards the ethanolic extract of Asteriscus pygmaeus.

Table 2 Antimicrobial study of the Asteriscuspygmaeusextracts

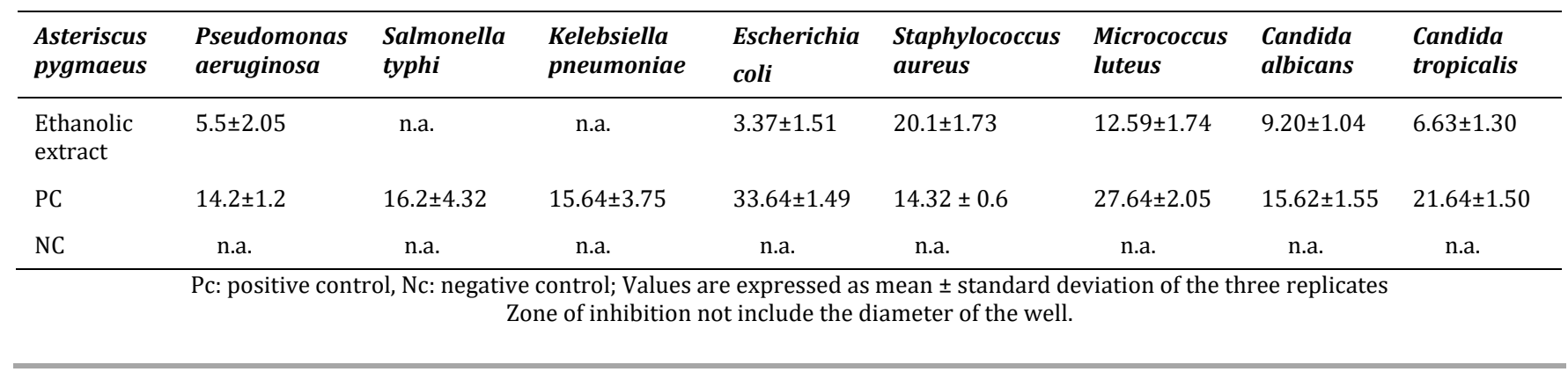

\section{Conclusion}

It was finally concluded that the ethanolic extract of Asteriscus pygmaeus has high antioxidant activity and moderate antibacterial activity due to its polyphenolic content. Staphylococcus aureus and Micrococcus luteus were the most susceptible microorganisms, whereas Salmonella typhiand Kelebsiella pneumonia were the most resistant bacteria. Moreover the phytochemical screening of the ethanolic extract lead to isolation of a new compound: 6Hydroxykaempferol 6-methyl ether-4' glucopyranoside (1), together with eight known metabolites.

\section{Compliance with ethical standards}

\section{Acknowledgments}

The authors would like to acknowledge with thanks to the National Research Centre, Dokki, Cairo, Egypt for the facilities provided for such an accomplishment.

\section{References}

[1] Tepe B, Daferera D, Sokmen A, Sokmen M and Polissiou M. (2005). Antimicrobial and antioxidant activities of essential oil and various extracts of salvia tomentosa miller (lamiaceae). Food Chem, 90, 333-340.

[2] Khanna D, Sethi G, Ahn KS, Pandey MK, Kunnumakkara AB, Sung B, Aggarwal A and Aggarwal BB. (2007). Natural products as a gold mine for arthritis treatment. Curr Opin Pharmacol,7(3), 344-351.

[3] Fusco D, Colloca G, Lo Monaco MR and Cesari M. (2007). Effects of antioxidant supplementation on the aging process. J Clin Interv Aging, 2, 377-387.

[4] Loizzo MR, Tundis R,Conforti F, Saab AM, Statti GA and Menichini F. (2007). Composition and $\alpha$-amylase inhibitory effect of essential oils from cedrus libani. Fitoterapia, 78, 323-326.

[5] Cristofari G, Znini M, Majidi L, Mazouz H, omi P, Costa J and Paolini J. (2012). Chemical Diversity of Essential Oils from Asteriscus graveolens (Forssk.) Less: Identification of cis-8-Acetoxychrysanthenyl Acetate as a New Natural Component, Chemistry \& Biodiversity, 9, 727- 738.

[6] Ezzat MI, Ezzat SM, El Fishawy AM, El Deeb KS and El Toumy SA. (2016). A new acylated flavonol from the aerial parts of Asteriscus maritimus (L.) Less (Asteraceae), Journal Natural Product Research, 30, 1753-1761.

[7] Ahmed AA, Ishak M S, Micheal H N, El-Ansari M A and El-Sissi H I.(1991). Flavonoids of Asteriscus graveolens, J. Nat. Prod, 54 (4), 1092-1093.

[8] Dawidar AM, Ayyad SN, Abdel-Mogib M and Alarif WM. (2005). Humulene Sesquiterpene Lactones from Asteriscus schimperi, J. saudi chem. soc, 9, 137-142.

[9] Akssira M, Mellouki F, Salhi A, Alilou H, Saouf A, El Hanbali F, Arteaga JF and Barrero AF. (2006). Naupliolide, a sesquiterpene lactone with a novel tetracyclic skeleton from Nauplius graveolens susp odorus, Tetrahedron Lett. 47, 6719-6721. 
[10] Ramdanea F, Essid R, Mkadmini K, Hammami M, Fares N, Mahammed MH, El Ouassis D, Tabbene O, Limam F and Hadj MDO. (2017). Phytochemical composition and biological activities of Asteriscus graveolens (Forssk) extracts, Process Biochemistry, 56, 186-192.

[11] Benchelah AC, Bouziane H and Maka M. (2004). Fleurs du Sahara, arbres et arbustes, voyage au cœur de leurs usages avec les Touaregs du Tassili, Phytotherapie, 2, 191-197.

[12] Boussaada O, Chriaa J, Nabli R, Ammar S, Saidana D, Mahjoub MA, Chraeif I, Helal AN and Mighr Z. (2008). Antimicrobial and antioxidant activities of methanol extracts of Evax pygmaea (Asteraceae) growing wild in Tunisia. World Journal of Microbiology and Biotechnology, 24 (8), 1289-1296.

[13] Mativandlela SPN, Lall N and Meyer JJN. (2006). Antibacterial, antifungal and antitubercular activity of (the roots of) Pelargonium reniforme (CURT) and Pelargonium sidoides (DC) (Geraniaceae) root extracts. South African Journal of Botany,72, 232-237.

[14] Askarne L, Talibi I, Boubaker H, Boudyach EH, Msanda F, Saadi B and Ben Aoumar AA. (2013). Use of Moroccan medicinal plant extracts as botanical fungicide against citrus blue mould, Lett. Appl. Microbiol, 56(1), 37-43.

[15] Sarg TM, El-Dahmy SI, Ateya AM and Abdel-Fattah HA. (1994). Two new bisabolone hydroperoxides and biological activity of Asteriscus graveolens ,Fitoterapia, 65, 241-244.

[16] Saraswathi J, Venkatesh K, Baburao N, Hilal MH and Roja Rani A. (2011). Phytopharmacological importance of pelargonium species. Journal of Medicinal Plants Research, 5(2), 587-2598.

[17] Gamez E JC, Luyengi L, Lee SK, Zhu LF, Zhou HBN, Fong HS, Pezzuto JM and Kinghorn AD. (1998). Antioxidant flavonoid glycosides from Daphniphyllum calycinum, J. Nat. Prod., 61, 706-708.

[18] Kumar G, Karthik L and Rao KVB. (2010). Phytochemical composition and in vitro antimicrobial activity of Bauhinia racemosa LAMK (caesalpinaceae), Int J Pharmaceutical Sciences Review and Research, 1(11), 51-58.

[19] Ajay Ka, Lokanatha Rai and Umesha KB. (2002). Evaluation of antibacterial activity of 3,5-dicyano-4,6-diaryl-4ethoxycarbonyl-piperid-2-ones, J Pharm Biomed Anal, 27(5), 837-840.

[20] Kumar G, Karthik L and Rao KVB. (2010). Antibacterial activity of aqueous extract of Calotropis gigantea leaves An in vitro study, Int J Pharmaceutical Sciences Review and Research, 4(2), 141-144.

[21] Smith DM, Glennie CW and Harborne JB. (1971). Identification of eupalitin, eupatolitin and patuletin glycosides in ipomopsis aggregata, Phytochemistry, 10, 3115-3120.

[22] Harborne JB. (1993).The Flavonoids Advances in Research Since 1986. In: Markham KR, Geiger H (eds.). ${ }^{1} \mathrm{H}$ nuclear magnetic resonance spectroscopy of flavonoids and their glycosides in hexadeutero dimethyl sulfoxide, Chapman and Hall, London, 441- 497.

\section{How to cite this article}

Shafik NH, Shafek REand Michael HN. (2019). Antioxidant, antibacterial activities and phytochemical screening of Asteriscus pygmaeus aerial parts ethanolic extract. GSC Biological and Pharmaceutical Sciences, 9(3), 41-46. 